\title{
Review of dutasteride/tamsulosin fixed-dose combination for the treatment of benign prostatic hyperplasia: efficacy, safety, and patient acceptability
}

\author{
This article was published in the following Dove Press journal: \\ Patient Preference and Adherence \\ 6 October 2011 \\ Number of times this article has been viewed
}

\section{Jack Barkin}

Humber River Regional Hospital, Toronto, Canada and Department of Surgery, University of Toronto, Toronto, Ontario, Canada
Correspondence: Jack Barkin

960 Lawrence Ave, West Suite 404,

Toronto, Ontario, Canada M6A 3B5

Tel + I 4162562737

Fax + I 4I62569098

Email j.barkin@rogers.com
Abstract: Lower urinary tract symptoms (LUTS) caused by benign prostatic hyperplasia $(\mathrm{BPH})$ will usually affect older men, of whom $50 \%$ over the age 60 years and almost $90 \%$ in their nineties will be bothered enough by their symptoms that they request some type of treatment. However, symptomatic bother may also affect men in their forties with a prevalence rate of almost $18 \%$. The International Prostate Symptom Score (IPSS) has become the most widely used and best validated questionnaire to allow the patient to quantify the severity of his LUTS/ BPH symptoms. This score has become the cornerstone in demonstrating the "rate of symptom response" for the patient who has been exposed to any type BPH management. Question 8 on the IPSS score is what is defined as the "Quality of Life" question or what is also termed the "Bothersome Index." The score out of 6 as declared by the patient will reflect the degree of concern that the patient is feeling about his symptoms and the reduction of the score after treatment is a statement of their improved quality of life. There are 2 families of accepted medical therapy to treat the symptoms of BPH and potentially prevent the most worrisome long-term sequelae of progression of BPH: urinary retention or the need for surgery. When defining the impact of the main types of medical therapy, the alpha blockers have been termed the "openers" and the 5 alpha-reductase inhibitors are described as the "shrinkers." Since they each offer a different mechanism of effect, the concept of combination therapy was raised and trialed many times over recent years. The final aspect of any medical therapy is the patient's satisfaction with the treatment and the side effects. In the CombAT (Combination of Avodart and Tamsulosin) trial a new assessment was developed and tested called the Patient's Perception of Study Medication (PPSM) which told the investigators if the patients, given free choice, would choose to take that combination of medication to treat their problem and stay on the medication.

Keywords: lower urinary tract symptoms, benign prostatic hyperplasia, Benign Prostatic Hyperplasia Impact Index, combination therapy, alpha blockers, 5 alpha reductase inhibitors, quality of life, BII, Patient's Perception of Study Medication

\section{Introduction}

For over 20 years men have been treated medically for the symptoms of what was always thought to arise from benign prostatic hyperplasia (BPH). Today we understand that the symptoms are more correctly termed lower urinary tract symptoms (LUTS). The bladder has 2 main functions, storage and voiding (emptying). The commonest cause for the man over the age of 50 years for LUTS is indeed BPH.

Many years ago, Barry et al developed what was to become the most widely accepted and utilized validated questionnaire to measure the severity of LUTS 
symptoms. The International Prostate Symptom Score (IPSS) is a quantification of the severity of symptoms as it is selfreported by the patient. ${ }^{1}$ This has become the gold standard in establishing the baseline and then follow-up score after any type (medical, natural, or surgical) of intervention for the management of BPH. Each question of the first 7 could be classified as either a "voiding" or a "storage" question.

A score of:

0 is defined as NO symptoms

$\leq 7$ is defined as MILD symptoms

$\geq 8$ and $\leq 19$ is defined as MODERATE symptoms

$\geq 19$ and $\leq 35$ is defined as SEVERE symptoms.

Barry also proved in clinical trials that a minimum of a 3-point improvement on the symptom scale was necessary for the patient to perceive the clinical improvement.

Question 8 on the IPSS score is the Quality of Life question or what is more aptly termed the "Bothersome Index."

This key question is "If you were to spend the rest of your life with your urinary condition the way it is now, how would you feel about that?" A score of 0 equates to "delighted" and a score of 6 equates to "terrible."

Again this is a self-reported declaration of the patient's perceived bother from his symptoms after considering his ability to tolerate the present degree of symptoms for the rest of his life.

I also define question 8 as the "motivational index." The higher the bothersome index, the more motivated the patient will be to accept the "risk/benefit" ratio discussion about the benefits of the proposed therapy balanced against the potential side effects of the medication. Kirby et al also determined that the $3 / 6$ is the cutpoint for the minimum number that the patient will report, which will indicate that he is willing to accept treatment for his symptoms. ${ }^{11}$

Another questionnaire used to measure quality of life (QoL) for BPH patients is called the BPH Impact Index (BII), which

- Assesses overall impact of BPH on a patient's general sense of well-being

- Measures aspects of physical discomfort, worry, and bother, all of which can be affected by BPH and its symptoms

- BPH Impact Index:

1. Over the past month how much physical discomfort did any urinary problems cause you?

2. Over the past month, how much did you worry about your health because of any urinary problems?
3. Overall, how bothersome has any trouble with urination been during the past month?

4. Over the past month, how much of the time has any urinary problem kept you from doing the kind of things you would usually do?

Total score from 0 to 13 (higher score $=$ worse $\mathrm{BPH}-$ related health status). ${ }^{2}$

It has been shown that BPH, if untreated, may progress. There are certain risk factors that will predict the progression of BPH/LUTS. Progression of BPH can have a dramatic impact on the patients well-being (Figure 1).

\section{Physiology}

There are two medical approaches to the management of $\mathrm{BPH}$, which work through the different receptors within the bladder and the prostate.

The alpha blockers block the smooth muscle receptors at the bladder neck, in the bladder, and within the prostate, thereby relaxing the tension that "opens" the bladder neck allowing for easier, stronger flow and a more complete emptying, which means less frequency, urgency, and nocturia. The response is very quick, in hours to a few days, but the long-term response is relatively short, where most men need an adjustment in dosage or movement to another therapy by 4 years. As was seen in the Medical Therapy of Prostate Symptoms (MTOPS) trial at 5.5 years, the alpha blocker doxozasin was able to provide better symptom response than the monotherapy of finasteride or placebo. ${ }^{8}$ However, alpha blockers do not prevent the progression of $\mathrm{BPH}$, which usually culminates in urinary retention and/or the need for surgery. ${ }^{9}$

The 5 alpha reductase (5ARI) inhibitors work through a different mechanism. They prevent the conversion of testosterone to dihydrotestosterone (DHT). It is the DHT, when bound to the RNA in the cells of the prostate, that stimulate growth of the cells and glands within the prostate. After 3-6 months of therapy the cells and prostate that has been deprived of DHT will shrink. There are 2 5ARI iso-enzymes, type 1 and type 2 . Finasteride will inhibit only the type 2 receptors whereas dutasteride will inhibit both type 1 and type 2. This extra inhibition results in a greater reduction of DHT of almost $95 \%$

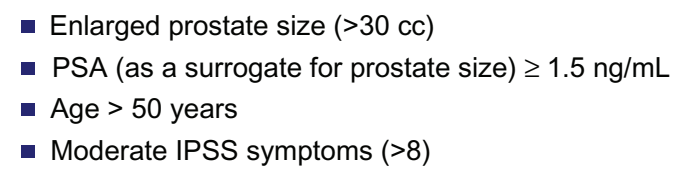

Figure I Risk factors for benign prostatic hyperplasia progression. ${ }^{3-7}$ Abbreviations: IPSS, International Prostate Symptom Score; PSA, prostate-specific antigen. 
versus $71 \% .{ }^{10}$ We do not yet know the exact minimum DHT threshold suppression to achieve maximum shrinkage of the gland through maximum and prolonged androgen receptor blockade within the prostate. The 5ARIs achieve a slow onset of response as demonstrated by the expected 6-month drop in the prostate-specific antigen (PSA), volume reduction of the gland, and the prevention of progression.

\section{History of combination therapy}

From the launch of the first alpha blocker and 5ARI in the early 1990s the concept of combination therapy was entertained (Figure 2). The hypothesis was that the synergistic effect of the two drugs would provide the early onset of symptom response from the alpha blocker and the longterm durability of symptom response and prevention of progression from the 5ARI. The concern was in the lack of knowledge as to whether there would also be synergy in the complications or side effects of the 2 drug families as well.

There were numerous trials, but the results of the early combination trials using finasteride and the non-selective alpha blockers (Predict: ${ }^{11}$ European - doxazosin and finasteride; Va-coop: ${ }^{12}$ American - terazosin and finasteride) were a disaster. The results showed that the finasteride monotherapy arm was no better than placebo when measuring symptom response.

In retrospect the faults were that the studies were too short (only 1 year) and the prostate volumes may have been too small $(<30 \mathrm{~mL})$ to reap the benefits of the 5ARI finasteride.

\section{Efficacy of long-term combination therapy}

The first long-term combination trial, MTOPS, which was performed only in the United States on 3047 men with

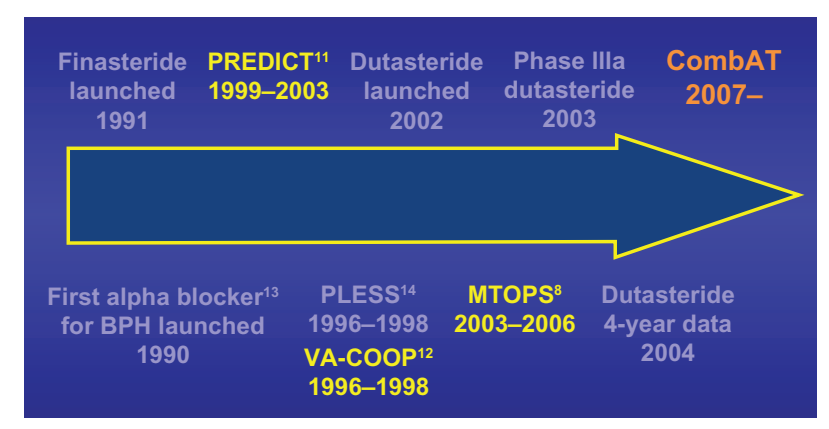

Figure 2 Milestones of changes in medical management of benign prostatic hyperplasia (BPH). moderate symptoms of BPH and a PSA $<4$, lasted for 5.5 years and compared monotherapy of doxozasin, finasteride, or placebo to the combination of doxozasin and finasteride. ${ }^{8}$

The results were very impressive in that they demonstrated a $67 \%$ risk reduction in progression of disease at 4.5 mean years of follow-up in the combination arm compared with placebo. There was an insignificant difference in the response in any of the arms compared with placebo at 1 year.

The same cohort also demonstrated a $66 \%$ risk reduction in developing acute urinary retention (AUR) or the need for surgery in the combination arm compared with placebo at study end.

An analysis of the response when the patients were stratified by prostate volume revealed that a volume of $30 \mathrm{~mL}$ was the minimum necessary to derive a clinically significant response in the 5ARI arm whether monotherapy or combination compared with placebo. ${ }^{15}$

QoL was a secondary endpoint in MTOPS (assessed using the Medical Outcomes Study Short Form-36 Health Survey instrument). However, no QoL outcomes for combination therapy have been published from MTOPS.

Dutasteride monotherapy trials had been performed and reported in 2004 in which the long-term effects of dutatsteride were compared with placebo. The results of the 4-year extended monotherapy trial showed an $80 \%$ better symptom response, 56\% PSA reduction, $27 \%$ volume reduction, and a $70 \%$ risk reduction in either AUR or the need for surgery. ${ }^{16}$

Tamsulosin had previously been recognized as a uroselective alpha blocker, which provided the maximum therapeutic effect while causing far less risk of cardiovascular side effects such as orthostatic hypotension, as was found in the nonselective alpha blockers like doxazosin. ${ }^{17}$

It had already been shown that dutasteride was very effective compared with placebo in men with BPH, especially in those with large prostates $(>30 \mathrm{~mL})$. As well, as previously stated the risk factors for BPH progression as determined at time of diagnosis were age $>50$ years, prostate volume $>30 \mathrm{~mL}$, and moderate symptoms on the IPSS ( $\geq 7)$.

Another recent consideration is the fact that it has been shown that the PSA in BPH can be a surrogate predictor of the prostate volume. One can virtually guarantee that if the PSA is $>1.5 \mathrm{ng} / \mathrm{mL}$, regardless of the age of the patient the actual prostate volume will be at least $30 \mathrm{~mL} .{ }^{18}$

Consequently, the Combination of Avodart and Tamsulosin (CombAT) trial had different inclusion criteria from MTOPS, which were recognized as defining a more "at 


\begin{tabular}{|c|c|c|}
\hline & CombAT & MTOPS \\
\hline \multirow[t]{4}{*}{ Treatment groups } & $\begin{array}{l}\text { Dutasteride } 0.5 \mathrm{mg} \\
\text { monotherapy }\end{array}$ & $\begin{array}{l}\text { Finasteride } 5 \text { mg } \\
\text { monotherapy }\end{array}$ \\
\hline & $\begin{array}{l}\text { Tamsulosin } 0.4 \mathrm{mg} \\
\text { monotherapy }\end{array}$ & $\begin{array}{l}\text { Doxazosin } 4 \text { or } 8 \mathrm{mg} \\
\text { monotherapy }\end{array}$ \\
\hline & $\begin{array}{l}\text { Dutasteride and tamsulosin } \\
\text { combination therapy }\end{array}$ & $\begin{array}{l}\text { Finasteride and doxazosin } \\
\text { combination therapy }\end{array}$ \\
\hline & & 口 Placebo \\
\hline $\mathbf{n}$ & 4844 & 3047 \\
\hline Location & International & US only \\
\hline \multicolumn{3}{|l|}{ Entry criteria } \\
\hline Age & $\geq 50$ & $\geq 50$ \\
\hline PV (cc) & $\geq 30$ & None \\
\hline PSA (ng/mL) & $\geq 1.5$ and $\leq 10$ & $\leq 10$ \\
\hline IPSS & $\geq 12$ & $8-30$ \\
\hline \multicolumn{3}{|l|}{ Primary endpoints } \\
\hline 2-year & Improvement in IPSS & None \\
\hline 4-year & $\begin{array}{l}\text { Reduction in risk of AUR or } \\
\text { surgery }\end{array}$ & $\begin{array}{l}\text { Composite endpoint of BPH } \\
\text { clinical progression }\end{array}$ \\
\hline
\end{tabular}

Figure 3 Comparison of baseline demographics and study designs of MTOPS and CombAT. ${ }^{19}$

Abbreviations: AUR, acute urinary retention; BPH, benign prostatic hyperplasia; IPSS, International Prostate Symptom Score; PV, prostate volume; PSA, prostate-specific antigen.

Note: Reprinted with permission from Roehrborn CG, Siami P, Barkin J, et al. The effects of combination therapy with dutasteride and tamsulosin on clinical outcomes in men with symptomatic benign prostatic hyperplasia: 4-year results from the CombAT study. Eur Urol. 2010;57(1):123-131.19 Copyright @ 2010 Elsevier.

risk" population for BPH progression. ${ }^{20}$ The average prostate volume in all 3 arms at the baseline was $55 \mathrm{~mL}$ and the average PSA was 4.0.

Based on all of these considerations no ethical review board in any of the 32 countries felt comfortable in requesting a placebo arm for the 4 years of the trial knowing that this population, without treatment, had a great chance of progressing, developing AUR, or needing surgery by the end of the trial. Therefore, only 3 arms were required: Monotherapy of
Tamsulosin or Dutatsteride, compared with the combination arm of Dutatsteride and Tamsulosin.

There were other significant differences as well (Figure 3).

The protocol was designed such that there was both a 2 -year and 4-year analysis. The primary endpoint at the 2-year mark was the change in the IPSS responders' scores from baseline comparing combination to the active treatment of tamsulosin (MTOPS compared with placebo).

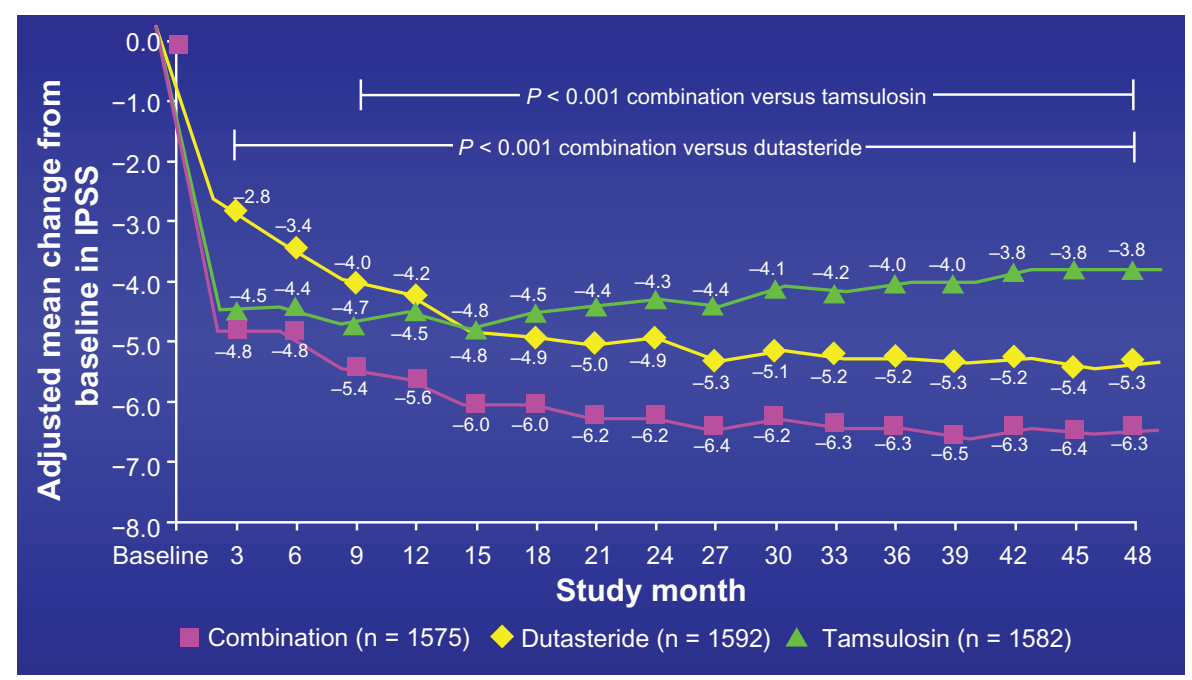

Figure 4 Mean change International Prostate Symptom Score (IPSS) from baseline: primary endpoint in 4-year CombAT trial.

Note: Reprinted with permission from Roehrborn CG, Siami P, Barkin J, et al. The effects of combination therapy with dutasteride and tamsulosin on clinical outcomes in men with symptomatic benign prostatic hyperplasia: 4-year results from the CombAT study. Eur Urol. 2010;57(I):123-131.19 Copyright (C) 2010 Elsevier. 


\section{Primary}

- Time to event/proportion of subjects with AUR or BPH-related surgery

\section{Secondary}

- Time to BPH-related clinical progression First of:

- Symptom deterioration by IPSS $\geq 4$ points

- Acute urinary retention

- Incontinence

- Recurrent UTI or urosepsis

- Renal insufficiency related to BPH

Figure 5 Four-year primary and secondary CombAT endpoints. ${ }^{21}$

Abbreviations: AUR, acute urinary retention; $\mathrm{BPH}$, benign prostatic hyperplasia; IPSS, International Prostate Symptom Score; UTI, urinary tract infection.

There were many secondary endpoints, which included percent with a $\geq 25 \%$ change in IPSS, change in prostate volume, $\mathrm{Q}_{\max }$ (peak uroflow rate) improvement in $\mathrm{mL} /$ second, BII, QoL as defined by question 8 in the IPSS as well as a newly developed assessment called the Patients Perception of Study Medication (PPSM).

In every endpoint measured at 2 years there was a significant improvement in the combination arm compared with either monotherapy arm, with a consistently and statistically better response than the tamsulosin arm. ${ }^{22}$

This was the first combination trial ever where the response as measured by the IPSS score was better in the
5ARI or combination arm than the alpha blocker. Until this study, it had always been reported when measuring symptom response, especially up to 4 years, that the alpha blocker would outperform the 5ARI. In MTOPS, when assessing IPSS response, doxozasin always achieved a lower IPSS score than finasteride even out to 5.5 years. In this study the crossover point where dutasteride monotherapy outperformed tamsulosin monotherapy occurred at 15 months and never reverted. ${ }^{19}$ Combination therapy surpassed tamsulosin in IPSS response as early as 3 months $^{22}$ (Figure 4).

\section{Acceptance QoL improvement with combination therapy}

The QoL responses were also very significant. It is the patient's feeling of improvement that will encourage him to continue in the study. Barry et al had previously determined that a 1.1 point improvement in question 8 or a 2-point improvement in the BII would be considered as a "marked" (slight, moderate, marked) clinical improvement and definitely perceived by the patient. Again the combination arm achieved both a clinically significant question 8 response compared with tamsulosin as early as 3 months $(-1.4$ vs -1.1$)$ as well as the "marked" BII response ( -2.1 vs -1.5$)$ by the end of 2 years. ${ }^{23}$

Two other significant clinical responses were seen by the end of the 2 years. The first was that there was a $55 \%$ reduction from the baseline PSA in the dutasteride or combination arm and a $12.5 \%$ increase from the baseline PSA in the

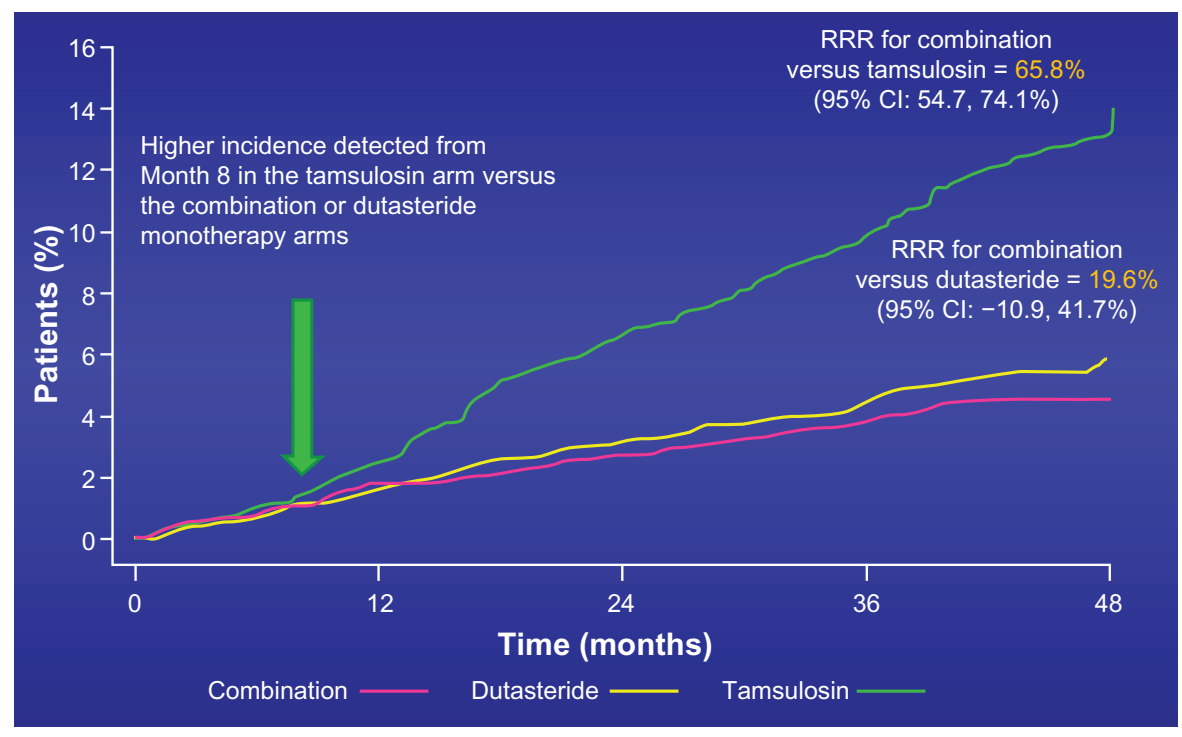

Figure 6 CombAT 4-year composite primary endpoint - time to first AUR or BPH surgery.

Note: Reprinted with permission from Roehrborn CG, Siami P, Barkin J, et al. The effects of combination therapy with dutasteride and tamsulosin on clinical outcomes in men with symptomatic benign prostatic hyperplasia: 4-year results from the CombAT study. Eur Urol. 2010;57(I): 123-131. ${ }^{19}$ Copyright @ 20I0 Elsevier.

Abbreviations: AUR, acute urinary retention; $\mathrm{BPH}$, benign prostatic hyperplasia; $\mathrm{Cl}$, confidence interval; RRR, relative risk reduction. 


\begin{tabular}{lccc} 
& $\begin{array}{c}\text { Combination } \\
(\mathrm{n}=1610)\end{array}$ & $\begin{array}{c}\text { Dutasteride } \\
(\mathrm{n}=1623)\end{array}$ & $\begin{array}{c}\text { Tamsulosin } \\
(\mathrm{n}=1611)\end{array}$ \\
At Year 4 & $\%$ & $\%$ & $\%$ \\
Clinical progression & $12.6 \%$ & $17.8 \%^{*}$ & $21.5 \% *$ \\
Risk reduction versus & & $31.2 \%$ & $44.1 \%$ \\
combination (95\% Cl) & & $(17.7 \%-42.5 \%)$ & $(33.6 \%-53.0 \%)$ \\
IPSS increase $\geq 4$ points & $8.6 \%$ & $13.1 \%^{*}$ & $14.2 \%^{*}$ \\
AUR & $1.6 \%$ & $2.3 \%$ & $5.1 \%$ \\
Incontinence & $3.0 \%$ & $3.7 \%$ & $4.0 \%$ \\
UTI & $0.2 \%$ & $0.3 \%$ & $0.3 \%$ \\
Renal insufficiency & $<0.1 \%$ & $0.1 \%$ & $0.4 \%$ \\
\hline
\end{tabular}

Figure 7 CombAT 4-year secondary endpoints - clinical progression. Notes: Rate based on ITT population; ${ }^{*} P<0.00$ I versus combination. Reprinted with permission from Roehrborn CG, Siami P, Barkin J, et al. The effects of combination therapy with dutasteride and tamsulosin on clinical outcomes in men with symptomatic benign prostatic hyperplasia: 4-year results from the CombAT study. Eur Urol. 2010;57(1):123-131. ${ }^{19}$ Copyright () 2010 Elsevier.

Abbreviations: AUR, acute urinary retention; $\mathrm{BPH}$, benign prostatic hyperplasia; IPSS, International Prostate Symptom Score; ITT, intention-to-treat; UTI, urinary tract infection.

tamsulosin arm. Also there was a $28 \%$ volume reduction in the dutasteride/tamsulosin combination arm, with no change or a slight increase from the baseline volume in the alpha blocker arm.

At 4 years the endpoints were more inclusive and the results even more significant (Figure 5). It is important to remember that these patients had average baseline volumes of $55 \mathrm{~mL}$ (proven by transrectal ultrasound measurements), average PSAs of 4.0, average IPSS score of 16.7 (almost in the "severe" range). Also all responses that were achieved were compared with the active treatment arm of tamsulosin, unlike MTOPS where the combination arm response was compared with placebo.

The most important consideration for a man who is at risk for $\mathrm{BPH}$ progression is the possibility that he will develop AUR or need surgery to correct the sequelae of his profound $\mathrm{BPH}$.

The 4-year primary composite endpoint of AUR or the need for surgery achieved significant results ${ }^{20}$ (Figure 6).

The patients in the combination arm of dutasteride and tamsulosin enjoyed a $66 \%$ risk reduction for developing these devastating problems compared with those in the active treatment tamsulosin arm. In the MTOPS trial there was a $67 \%$ risk reduction in these same endpoints, but in that case it was the combination of finasteride and doxozasin compared with placebo. ${ }^{8}$

All of the other secondary 4-year endpoints of clinical progression also had a statistically better response in the combination arm than either monotherapy $\operatorname{arm}^{19}$ (Figure 7).

The 4-year response as measured by the BII or question 8 was maintained and actually increased compared with the 2-year reported response. BII reached a -2.2 points, whereas

\section{- 12 questions covering six areas}

- Control of urinary symptoms

- Strength of urinary stream

- Two aspects of pain of urination

- Effect on usual activities

- Overall satisfaction

- Whether the respondent would ask their doctor for this medication

Figure 8 Description of Patient's Perception of Study Medicine Questionnaire (PPSM). ${ }^{14}$

Note: Seven-point scale (Qs I to II) or 'yes', 'no' or 'not sure' (QI2).

question 8 achieved a -1.6 points, both of which were statistically significant compared with tamsulosin. ${ }^{24}$

\section{PPSM}

The new parameter that was developed and validated specifically for this study was the PPSM (Figure 8). This was a questionnaire that tested the patient's appreciation of the study medication and their ultimate desire, after weighing the risks (side effects actually experienced) against the clinical benefits achieved, would they voluntarily choose and be compliant in taking that medicine.

The absolute improved response in the combination arm compared with either dutasteride or tamsulosin was statistically significant $(-7.0$ vs -5.5 vs -4.1 out of a maximum of 25 , respectively). ${ }^{19}$

Even more important was the overall acceptance of the combination therapy compared with the monotherapy arms (Figure 9).

\section{Safety and side effects}

It was shown that the combination was very effective. The question about whether the incidence of side effects as

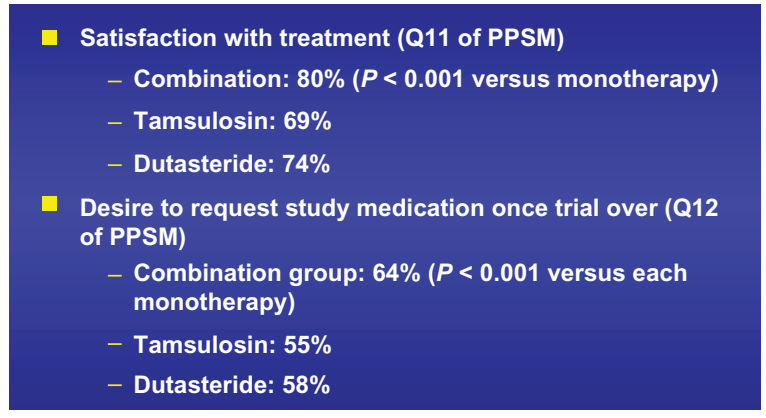

Figure 9 Patient's Perception of Study Medicine Questionnaire (PPSM) results for questions $\mathrm{II}$ and 12 . 


\begin{tabular}{lccc} 
Adverse events & $\begin{array}{c}\text { Combination } \\
(\mathrm{n}=1610) \%\end{array}$ & $\begin{array}{c}\text { Dutasteride } \\
(\mathrm{n}=1623) \%\end{array}$ & $\begin{array}{c}\text { Tamsulosin } \\
(\mathrm{n}=1611) \%\end{array}$ \\
\hline $\begin{array}{l}\text { Drug-related adverse events } \\
\text { occurring in } \geq 1 \text { of subjects } \\
\text { Erectile dysfunction }\end{array}$ & 9 & 7 & 5 \\
Retrograde ejaculation & 4 & $<1$ & 1 \\
Altered (decreased) libido & 4 & 3 & 2 \\
Ejaculation failure & 3 & $<1$ & $<1$ \\
Semen volume decreased & 2 & $<1$ & $<1$ \\
Loss of libido & 2 & 1 & 1 \\
Dizziness & 2 & $<1$ & 2 \\
Gynecomastia & 2 & 2 & $<1$ \\
Nipple pain & 1 & $<1$ & $<1$ \\
Breast tenderness & 1 & 1 & $<$
\end{tabular}

Figure 10 CombAT 4-year incidence of drug-related adverse events.

Note: Reprinted with permission from Roehrborn CG, Siami P, Barkin J, et al. The effects of combination therapy with dutasteride and tamsulosin on clinical outcomes in men with symptomatic benign prostatic hyperplasia: 4-year results from the CombAT study. Eur Urol. 2010;57(I):123-131. ${ }^{19}$ Copyright C 2010 Elsevier.

reported in either monotherapy arm would be less than, additive, or greater in the combination arm was reported.

The only side effect for which the total in the combination arm was greater than the sum of the reported incidences in either monotherapy arm was in the complaint related to ejaculatory dysfunction. In this area the combination of the decreased volume associated with the $5 \mathrm{ARI}$, when added to either the retrograde ejaculation or diminished release from the seminal vesicles, was experienced and reported by the patients more in the combination arm than in the 2 monotherapy arms combined ${ }^{19}$ (Figure 10).

As was reflected in the PPSM, there was no significant difference in the "drug related adverse events leading to study withdrawal" rates in the 3 arms when comparing combination with dutasteride with tamsulosin. The reported rates were $6 \%$, $4 \%$, and $4 \%$ respectively out of $>1600$ patients in each arm.

It is also important to be able to inform the patients that drug-related adverse events diminished over time, the incidence being about $12 \%$ in the first year, but only $2 \%$ in the fourth year. Therefore, it is important to encourage the patients to stay on the drugs, because if they do not get side effects in the first year, the chances of experiencing side effects later on is greatly diminished.

\section{Initiation and/or withdrawal of combination therapy}

If there is concern about the economics or potential long-term side effects of combination therapy, there is information to suggest that in $77 \%$ of patients who received combination (dutasteride and tamsulosin) therapy for 6 months followed by alpha blocker withdrawal, felt the same or better 6 months after stopping the alpha blocker. If their original IPSS was $>20$, this favored response was reached in only $56 \%$ of the men. ${ }^{25}$

It is also important to consider that if combination therapy is going to be started, it should be initiated early (adding 5ARI to alpha blocker) or simultaneously. For every month delay in adding the 5ARI, if a patient starts with alpha blocker monotherapy, a decrease in response of about $2 \%$ as measured at the end of 1 year. ${ }^{21}$

\section{Conclusion}

CombAT has clearly demonstrated that for the man with an enlarged prostate $(>30 \mathrm{~mL})$ and moderate symptom complaints, the combination of dutasteride and tamsulosin compared with monotherapy will provide the most effective and most durable long-term benefits. This was demonstrated in all parameters including symptom response, lack of progression, and the development of AUR or the need for surgery. Moreover, the combination is safe with very few significant side effects or adverse events. Finally, if given the choice a greater number of patients would choose and continue to regularly take the combination therapy over either monotherapy.

\section{Disclosure}

The author has been an investigator, medical advisory board member, speaker and publisher for 5ARI's and Alpha Blockers produced by Merck, GSK, Boeringer, Abbott and Sanofi pharmaceuticals. 


\section{References}

1. Barry MJ, Fowler FL, O'Leary MP, et al. The American Urological Association Symptom Index for benign prostatic hyperplasia. $J$ Urol. 1992;148(5):1549-1557.

2. Barry MJ, Williford WO, Chang W, et al. Benign prostatic hyperplasia specific health status measures in clinical research: how much change in the American Urological Association symptom index and the benign prostatic hyperplasia impact index is perceptible to patients? $J$ Urol. 1995;154(5):1770-1774.

3. Anderson JB, Roehrborn CG, Schalken JA, Emberton M. The progression of benign prostatic hyperplasia: examining the evidence and determining the risk. Eur Urol. 2001;39(4):390-399.

4. Madersbacher S, Marszalek M, Lackner J, Berger P, Schatzl G. The long-term outcome of medical therapy for BPH. Eur Urol. 2007;51(6):1522-1533.

5. Marks LS, Roehrborn CG, Andriole GL. Prevention of benign prostatic hyperplasia disease. J Urol. 2006;176(4 Pt 1):1299-1306.

6. Djavan B, Waldert M, Ghawidel C, Marberger M. Benign prostatic hyperplasia progression and its impact on treatment. Curr Opin Urol. 2004;14(1):45-50.

7. Roehrborn CG. Definition of at-risk patients: baseline variables. $B J U$ Int. 2006;97(Suppl 2):7-11; discussion 21-22.

8. McConnell JD, Roehrborn CG, Bautista OM, et al. The long-term effect of doxazosin, finasteride, and combination therapy on the clinical progression of benign prostatic hyperplasia. $N$ Engl $J$ Med. 2003;349(25):2387-2398.

9. Oelke M, Bachmann A, Descazeaud M, et al. EAU Guidelines on Conservative Treatment of Non-neurogenic Male LUTS. Arnhem, The Netherlands: European Association of Urology; 2010. Available from: http://www.uroweb.org/gls/pdf/BPH\%202010.pdf. Accessed June 24, 2011.

10. Clark RV, Hermann DJ, Cunningham GR, Wilson TH, Morrill BB, Hobbs S. Marked suppression of dihydrotestosterone in men with benign prostatic hyperplasia by dutasteride, a dual 5 alpha-reductase inhibitor. J Clin Endocrinol Metab. 2004;89:2179-2184.

11. Kirby RS, Roehrborn C, Boyle P, et al. Efficacy and tolerability of doxazosin and finasteride, alone or in combination, in treatment of symptomatic benign prostatic hyperplasia: the Prospective European Doxazosin and Combination Therapy (PREDICT) trial. Urology. 2003;61(1):119-126.

12. Lepor H, Williford WO, Barry MJ. The efficacy of terazosin, finasteride, or both in benign prostatic hyperplasia. Veterans Affairs Cooperative Studies Benign Prostatic Hyperplasia Study Group. $N$ Engl J Med. 1996;335(8):533-539.

13. Lepor H. Nonoperative management of benign prostatic hyperplasia. J Urol. 1989;141:1283-1289.

14. McConnell JD, Bruskewitz R, Walsh P, et al. The effect of finasteride on the risk of acute urinary retention and the need for surgical treatment among men with benign prostatic hyperplasia. $N$ Engl $\mathrm{J} \mathrm{Med}$. 1998;338:557-563.
15. Kaplan SA, McConnell JD, Roehrborn CG, et al. Combination therapy with doxazosin and finasteride for benign prostatic hyperplasia in patients with lower urinary tract symptoms and a baseline total prostate volume of $25 \mathrm{ml}$ or greater. $J$ Urol. 2006;175(1):217-22; discussion 220-221.

16. Debruyne F, Barkin J, van Erps P, et al. Efficacy and safety of long-term treatment with the dual 5 alpha-reductase inhibitor dutasteride in men with symptomatic benign prostatic hyperplasia. Eur Urol. 2004;46(4):488-495.

17. Abrams P, Schulman CC, Vaage S. Tamsulosin, a selective alpha $1 \mathrm{c}$-adrenoceptor antagonist: a randomized, controlled trial in patients with benign prostatic "obstruction" (symptomatic BPH). The European Tamsulosin Study Group. Br J Urol. 1995;76(3):325-336.

18. Roehrborn C, Boyle P, Gould AL, Waldstreicher J. Serum prostatespecific antigen as a predictor of prostate volume in men with benign prostatic hyperplasia. Urology. 1999;53(3):581-589.

19. Roehrborn CG, Siami P, Barkin J, et al. The effects of combination therapy with dutasteride and tamsulosin on clinical outcomes in men with symptomatic benign prostatic hyperplasia: 4-year results from the CombAT study. Eur Urol. 2010;57(1):123-131.

20. Siami P, Roehrborn CG, Barkin J, et al. Combination therapy with dutasteride and tamsulosin in men with moderate-to-severe benign prostatic hyperplasia and prostate enlargement: the CombAT (Combination of Avodart and Tamsulosin) trial rationale and study design. Contemp Clin Trials. 2007;28(6):770-779.

21. Naslund M, Eaddy MT, Hogue SL, Kruep EJ, Shah MB. Impact of delaying 5-alpha reductase inhibitor therapy in men on alpha-blocker therapy to treat BPH: assessment of acute urinary retention and prostaterelated surgery. Curr Med Res Opin. 2009;25(11):2663-2669.

22. Roehrborn C, Siami P, Barkin J, et al. The effects of dutasteride, tamsulosin and combination therapy on lower urinary tract symptoms in men with benign prostatic hyperplasia and prostatic enlargement: 2-year results from the CombAT study. J Urol. 2009;179(2):616-621; discussion 621.

23. Barkin J, Roehrborn C, Siami P, et al. Effect of dutasteride, tamsulosin and the combination on patient-reported quality of life and treatment satisfaction in men with moderate-to-severe benign prostatic hyperplasia: 2-year data from the CombAT trial. BJU Int. 2008;103(7):919-926.

24. Montorsi F, Henkel T, Geboers A, et al. Effect of dutasteride, tamsulosin and the combination on patient-reported quality of life and treatment satisfaction in men with moderate-to-severe benign prostatic hyperplasia: 4-year data from the CombAT study. Int $J$ Clin Pract. 2010;64(8):1042-1051.

25. Barkin J, Guimarães M, Jacobi G, Pushkar D, Taylor S, van Vierssen Trip $\mathrm{OB}$. Alpha-blocker therapy can be withdrawn in the majority of men following initial combination therapy with the dual 5alpha-reductase inhibitor dutasteride. Eur Urol. 2003;44(4):461-466.
Patient Preference and Adherence

\section{Publish your work in this journal}

Patient Preference and Adherence is an international, peer-reviewed, open access journal focusing on the growing importance of patient preference and adherence throughout the therapeutic continuum. Patient satisfaction, acceptability, quality of life, compliance, persistence and their role in developing new therapeutic modalities and compounds to

\section{Dovepress}

optimize clinical outcomes for existing disease states are major areas of interest. This journal has been accepted for indexing on PubMed Central. The manuscript management system is completely online and includes a very quick and fair peer-review system. Visit http://www.dovepress.com/ testimonials.php to read real quotes from published authors. 